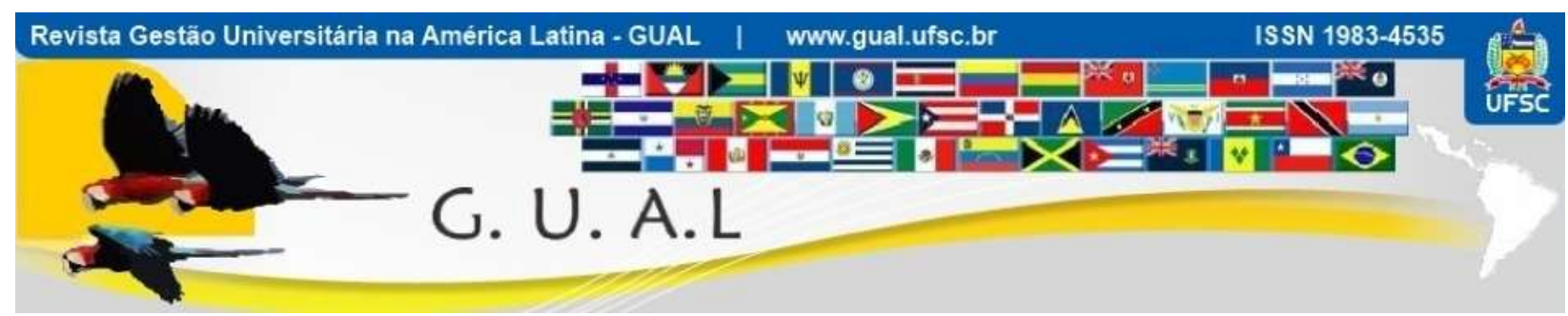

DOI: https://doi.org/10.5007/1983-4535.2021.e76341

\title{
A CONTRIBUIÇÃO DA GESTÃO DE PROJETOS PARA A ELABORAÇÃO DO PLANO DE DESENVOLVIMENTO INSTITUCIONAL (PDI) EM INSTITUIÇÕES DE ENSINO SUPERIOR
}

\section{CONTRIBUTION OF PROJECT MANAGEMENT TO THE PREPARATION OF THE INSTITUTIONAL DEVELOPMENT PLAN (PDI) IN HIGHER EDUCATION INSTITUTIONS}

Odair Schmidt, Especialista https://orcid.org/0000-0003-3627-484X odaximite@gmail.com Universidade Estadual do Oeste do Paraná | Programa de Pós-Graduação em Administração e Ciências Contáveis

Chapecó | Santa Catarina | Brasil

Silvana Veroneze, Especialista https://orcid.org/0000-0002-7990-5464 silvanaveroneze@gmail.com Universidade Estadual do Oeste do Paraná | Programa de Pós-Graduação em Administração e Ciências Contáveis Chapecó | Santa Catarina | Brasil

Cleunice Zanella, Doutora https://orcid.org/0000-0001-8243-9022 cleunice@unochapeco.edu.br

Universidade Estadual do Oeste do Paraná | Programa de Pós-Graduação em Administração e Ciências Contáveis Chapecó | Santa Catarina | Brasil

Recebido em 04/agosto/2020

Aprovado em 24/fevereiro/2021

Publicado em 01/maio/2021

Sistema de Avaliação: Double Blind Review

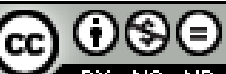

Esta obra está sob uma Licença Creative Commons Atribuição-Uso. 


\title{
RESUMO
}

O objetivo do estudo é analisar a contribuição da Gestão de Projetos para a elaboração do PDI em Instituições de Ensino Superior. Trata-se de um estudo de múltiplos casos com abordagem qualitativa do tipo descritiva. A coleta dos dados deu-se por meio de entrevista semiestruturada, as quais foram aplicadas a três gestores que possuem expertise sobre o PDI. A amostra foi composta por três IES, de personalidade jurídica pública estadual, pública federal e comunitária. Os dados foram analisados por meio da técnica de análise de conteúdo. Os resultados apontam que o processo de elaboração do PDI evidencia características da gestão de projetos, principalmente nas fases de início, meio e fim. Os achados apontam que durante o ciclo de elaboração do PDI são utilizadas algumas áreas do PMBOK, tais como: gerenciamento da integração, qualidade, escopo, cronograma, recurso, comunicações e gerenciamento das partes interessadas. Constatou-se ainda que as universidades têm adotado das técnicas e ferramentas de desempenho e gestão: opinião especializada, coleta de dados, habilidades interpessoais e de equipes, reuniões, gerenciamento de informações e gerenciamento de conhecimentos, sendo possível concluir ainda que o gerenciamento de projetos pode colaborar na elaboração do PDI.

Palavras-chave: Plano de Desenvolvimento Institucional (PDI). Gestão de Projetos. Instituições de Ensino Superior (IES).

\begin{abstract}
The objective of the study is to analyze the contribution of Project Management to the elaboration of the Higher Education Institutions (IDP). This is a multiple case study with a qualitative, descriptive approach. Data collection took place through semi-structured interviews, which were applied to three managers who have expertise on the PDI. The sample consisted of three HEIs, with state, federal and community public legal personality. The data were analyzed using the content analysis technique. The results show that the IDP elaboration process shows characteristics of project management, mainly in the beginning, middle and end phases. The findings indicate that during the IDP elaboration cycle, some areas of the PMBOK are used, such as: integration management, quality, scope, schedule, resource, communications and stakeholder management. It was also found that universities have adopted performance and management techniques and tools: expert opinion, data collection, interpersonal and team skills, meetings, information management and knowledge management, and it is possible to conclude that the management of projects can collaborate in the elaboration of the IDP.
\end{abstract}

Keywords: Institutional Development Plan (IDP). Project management. Higher education institutions (HEI). 


\section{INTRODUÇÃO}

Por meio da Lei $\mathrm{n}^{\circ} 10.861$ de 14 de abril de 2004, o governo brasileiro instituiu o Sistema Nacional de Avaliação da Educação Superior (SINAES). Em seu Art. $1^{\circ}$ consta que o sistema possui " [...] o objetivo de assegurar o processo nacional de avaliação das instituições de educação superior, dos cursos de graduação e do desempenho acadêmico de seus estudantes, nos termos do art $9^{\circ}$, VI, VIII e IX, da Lei n ${ }^{\circ}$ 9.394, de 20 de dezembro de 1996." (BRASIL, 2004). De acordo com a normativa, a avaliação das instituições, dos cursos e do desempenho dos estudantes, constitui os três eixos temáticos principais que necessitam estar estruturados e previstos no chamado Plano de Desenvolvimento Institucional (PDI) de cada IES (SEGNREICH, 2015).

Este Plano visa promover melhoria nos padrões de qualidade da educação superior brasileira (BRASIL, 2004), a uniformidade das atividades e gestão administrativa e acadêmica (MAGRO; RAUSCH, 2012) das IES públicas, comunitárias e privadas. Portanto, além de abordar informações sobre a identidade institucional, precisa estar estreitamente articulado com a prática e os resultados da avaliação institucional (MAGRO; RAUSCH, 2012). Desse modo, o PDI torna-se um instrumento indispensável para o planejamento e a gestão das IES brasileiras, em consonância às normas legais.

A elaboração do PDI pode ser compreendida como o planejamento e execução de um projeto. A partir da conclusão do projeto, inicia-se a execução das atividades planejadas. Sendo o PDI um projeto institucional, pois ultrapassa uma visão atual da gestão e dos aspectos conjunturais (UFPE, 2019), torna-se necessário fazer sua gestão, sendo possível utilizar de metodologias para gerenciamento de projetos.

A gestão de projetos gradativamente tornou-se um fator fundamental no desempenho de organizações tanto no setor público quanto no setor privado. A adoção de Gerenciamento de Projetos foi inserida nas práticas administrativas como tentativa de redução, solução de fracassos, estouro de prazo, orçamento, redefinições de escopo, além de falhas na prestação de contas, em projetos diversificados e estruturas de diferentes tamanhos (CARVALHO; PISCOPO, 2014; SILVA, 2015).

De acordo com o Guia do Conhecimento em Gerenciamento de Projetos (PMI, 2017) o gerenciamento de projetos pode ser entendido como a área da administração que tem como objetivo a aplicação de conhecimentos, habilidades, ferramentas e técnicas para elaboração de 
atividades envolvendo um projeto a fim de cumprir os seus requisitos, dentro do prazo determinado (PMI, 2017).

Nesta perspectiva, pode-se inferir que as IES brasileiras têm vinculado o planejamento estratégico com a elaboração do Plano de Desenvolvimento Institucional (PDI) (SILVA, 2013), sendo a gestão de projetos um meio para sua elaboração, visto que o planejamento estratégico institucional, para ser eficaz, requer a condução de um conjunto de mecanismos e etapas e o gerenciamento de projetos pode colaborar no processo dessa elaboração (SILVA et al., 2014), uma vez que segue sistematicamente as fases de início, meio e fim (VERZUH, 2000; HELDMAN, 2005; VIANA, 2005; FIGUEIREDO, FIGUEIREDO, 2003; VARGAS, 2009; SILVA et al., 2013; PMI, 2017), visto que um projeto pode ser compreendido como um conjunto de atividades correlacionadas visando alcançar um objetivo temporal predeterminado (PMI, 2017; VARGAS, 2009; HELDMAN, 2005; VIANA, 2005; FIGUEIREDO, FIGUEIREDO, 2003).

Dessa forma, depreende-se que o PDI pode ser considerado como um dos principais projetos de Gestão da IES brasileiras. Neste contexto, a problemática deste estudo pode ser configurada da seguinte forma: Como a Gestão de Projetos contribui na elaboração do Plano de Desenvolvimento Institucional em Instituição de Ensino Superior?

Objetivou-se analisar a contribuição da Gestão de Projetos para a elaboração do Plano de Desenvolvimento Institucional em Instituições de Ensino Superior. Para tanto, foram analisadas três IES de diferentes personalidades jurídicas, sendo elas de cunho pública federal, estadual e comunitária, localizadas no Oeste Catarinense. Este estudo justifica-se pela necessidade de conhecer a importância da contribuição da Gestão de Projetos na elaboração PDI como um dos principais instrumentos de planejamento, gestão e avaliação das IES brasileiras.

Esse estudo justifica-se pelo fato de que após realizada uma ampla revisão literária sobre o tema, verificou-se a inexistência de produções acadêmicas que analisam o processo de elaboração do PDI em instituições de diferentes naturezas jurídicas e com aprofundamento nos 5 grupos de gerenciamento de projetos, mencionados no guia do conhecimento em gerenciamento de projetos (PMBOK). Assim, espera-se que os resultados da pesquisa possam demonstrar como o gerenciamento de projetos pode conduzir gestores universitários em práticas administrativas, acadêmicas e tomada de decisões. 


\section{REVISÃO DA LITERATURA}

\subsection{O GERENCIAMENTO DE PROJETOS NA ELABORAÇÃO DO PLANO DE DESENVOLVIMENTO INSTITUCIONAL (PDI)}

O Plano de Desenvolvimento Institucional (PDI) é um instrumento normativo construído coletivamente pela comunidade acadêmica nas instituições de ensino superior, tendo como objetivos identificar a Instituição quanto à sua identidade funcional, à missão a que se propõe, às diretrizes pedagógicas que orientam suas ações, à sua estrutura organizacional e às atividades acadêmicas que desenvolve e tem intenção de desenvolver (BRASIL, 2002). Assim, contempla o cronograma e a metodologia de implementação dos objetivos e metas, de forma que estejam coerentes e articulados às ações previstas, sua qualidade e o orçamento destinado para sua realização.

O PDI, após concluído, vigorará pelo período de cinco anos e deverá apresentar indicadores de desempenho que possibilitem avaliar em conjunto com outras ferramentas institucionais, a situação atual e futura da IES, com vistas a sanar deficiências que tenham sido identificadas. (BRASIL, 2004).

Por meio do PDI as IES dispõe de uma ferramenta de cunho estratégico e dinâmico que permite o aprimoramento de diferentes dimensões de atuação, tais como: perfil institucional; gestão institucional (organização administrativa, organização e gestão pessoal, políticas de atendimento aos discentes); organização acadêmica (organização didáticopedagógica, oferta de cursos e programas); infraestrutura; aspectos financeiros e orçamentários; e avaliação e desenvolvimento institucional (MAGRO, RAUSCH, 2012).

\subsection{GERENCIAMENTO DE PROJETOS}

O desenvolvimento de projetos exige interligação de competências e habilidades nos diversos níveis hierárquicos organizacionais (STOIAN; GILMAN, 2017) e, nesse sentido, a adoção de gerenciamento de projetos torna-se um instrumento constante nas dinâmicas diárias das organizações, que trabalhado em conjunto com a inovação contribui para tomada de decisões e ao desempenho organizacional (MARTENS; CARVALHO, 2017).

Nesse sentido, o Processo de Gerenciamento de Projetos pode ser compreendido como sendo o conjunto de ferramentas e técnicas, que fornece às organizações uma base sólida para o alcance de seus objetivos, pode ser definido ainda, como o esforço temporário, não necessariamente de curta duração, despendido para produzir um produto, serviço ou resultado 
exclusivo (PMI, 2017). Assim, um projeto caracteriza-se por uma sequência clara e lógica das etapas, contendo início, meio e fim, visando atingir o objetivo definido, para isso é fundamental que o tempo, custos, recursos e qualidade estejam conduzidos dentro dos parâmetros predeterminados (VARGAS, 2009). Para que o projeto atinja a eficácia é fundamental a sintonia das distintas áreas funcionais com as estratégias organizacionais e o conjunto de projetos em desenvolvimento (OLIVEIRA et al., 2018).

Turner (2008) e PMI (2017) explicam que o Gerenciamento de Projetos dispõe de um conjunto de habilidades, ferramentas e técnicas fundamentadas em princípios normativos para condução do plano proposto em realidade, de maneira a ampliar a probabilidade de sucesso do projeto. Assim, para que o plano de projetos seja desenvolvimento de maneira eficaz é fundamental a utilização das seguintes ferramentas e técnicas: opinião especializada (expertise de indivíduos ou grupos com conhecimento ou treinamento especializado), coleta de dados (brainstorming, listas de verificação, grupos de discussão e entrevistas), habilidades interpessoais e de equipes (gerenciamento de conflitos e facilitação) reuniões, gerenciamento de informações e gerenciamento de conhecimentos (conectam pessoas para que possam trabalhar juntas e criar novos conhecimentos) (PMI, 2017). De forma inovadora, busca-se a coordenação entre o esforço humano, material e recursos financeiros, para alinhar-se ao escopo de trabalho, obedecendo os limites de custo e tempo (TURNER; MULLER, 2003).

O Gerenciamento de Projetos abrange cinco grupos no qual são executados pela equipe para categorizar a operacionalização das atividades e supervisionar os transmites até atingir os objetivos do projeto. Apresentam-se da seguinte forma: (i) Grupo de Processos de Iniciação (formaliza-se o início do projeto e os trâmites iniciais, alinha-se os anseios das partes interessadas ao objetivo do projeto, definindo o escopo e delimitando os recursos financeiros iniciais); (ii) Grupo de Processos de Planejamento (busca-se definir de forma criteriosa o escopo do projeto, os recursos, a equipe responsável, bem como a definição de outros detalhes importantes para construção do projeto); (iii) Grupo de Processos de Execução (gerenciar o engajamento entre as partes interessadas, os recursos planejados e as atividades que vêm sendo executadas, em consonância com os requisitos do projeto e plano elaborado); (iv) Grupo de Processos de Monitoramento e Controle (visa acompanhar o desempenho das atividades, comparando o executado com o planejado); (v) Grupo de Processos de Encerramento (conclusão ou fechamento formal do projeto, com a entrega do produto ou serviço) (PMI, 2017). 
O Guia PMBOK, além de abordar os Grupos de Processos, classifica os processos em dez Áreas de Conhecimento, conforme apresentam-se no quadro a seguir.

Quadro 1 Áreas de conhecimento em Gerenciamento de Projetos

\begin{tabular}{|c|c|}
\hline $\begin{array}{c}\text { Áreas de } \\
\text { Conhecimento }\end{array}$ & Descrição \\
\hline $\begin{array}{l}\text { Gerenciamento da } \\
\text { integração }\end{array}$ & $\begin{array}{l}\text { Trata-se de integrar, unificar e articular os vários processos e atividades de } \\
\text { gerenciamento de projetos, garantindo que as partes interessadas trabalhem de maneira } \\
\text { integrada. }\end{array}$ \\
\hline $\begin{array}{l}\text { Gerenciamento do } \\
\text { escopo }\end{array}$ & $\begin{array}{l}\text { Busca assegurar que o projeto contemple todo o trabalho necessário, de forma objetiva, } \\
\text { para conclusão com sucesso. }\end{array}$ \\
\hline $\begin{array}{l}\text { Gerenciamento do } \\
\text { cronograma }\end{array}$ & $\begin{array}{l}\text { Inclui os processos necessários para cumprimento dos prazos e responsabilidade, de } \\
\text { forma a gerenciar o término pontual do projeto. }\end{array}$ \\
\hline $\begin{array}{l}\text { Gerenciamento dos } \\
\text { custos }\end{array}$ & $\begin{array}{l}\text { Nesta área inclui-se os processos envolvidos como as estimativas, financiamentos, } \\
\text { gerenciamento e controle dos custos, a fim de que o projeto possa ser terminado dentro } \\
\text { do orçamento aprovado. }\end{array}$ \\
\hline $\begin{array}{l}\text { Gerenciamento da } \\
\text { qualidade }\end{array}$ & $\begin{array}{l}\text { Engloba os processos e atividades da organização para o cumprimento de políticas de } \\
\text { qualidade de maneira que o projeto satisfaça os requisitos pelos quais foi elaborado. }\end{array}$ \\
\hline $\begin{array}{l}\text { Gerenciamento dos } \\
\text { recursos }\end{array}$ & $\begin{array}{l}\text { Inclui os recursos necessários para organizar e gerenciar a equipe do projeto, busca } \\
\text { aproveitar de maneira proveitosa o conhecimento e habilidade dos membros dessa } \\
\text { equipe. }\end{array}$ \\
\hline $\begin{array}{l}\text { Gerenciamento das } \\
\text { comunicações }\end{array}$ & $\begin{array}{l}\text { Elenca os processos necessários para que informações do projeto possam abranger } \\
\text { todos os processos e pessoas envolvidas assegurando que a comunicação seja eficaz e } \\
\text { apropriada. }\end{array}$ \\
\hline $\begin{array}{l}\text { Gerenciamento dos } \\
\text { riscos }\end{array}$ & $\begin{array}{l}\text { Visa incluir os processos de condução de planejamento, identificação e análise de } \\
\text { gerenciamento de risco, essas ações visam obter respostas de controle a riscos e a } \\
\text { identificar tanto eventos positivos quanto negativos. }\end{array}$ \\
\hline $\begin{array}{l}\text { Gerenciamento das } \\
\text { aquisições }\end{array}$ & $\begin{array}{l}\text { Efetua os trâmites necessários para comprar ou adquirir produtos, serviços ou } \\
\text { resultados externos à equipe do projeto. }\end{array}$ \\
\hline $\begin{array}{l}\text { Gerenciamento das } \\
\text { partes interessadas }\end{array}$ & $\begin{array}{l}\text { Identificar todas as partes envolvidas no gerenciamento do projeto, analisar suas } \\
\text { expectativas e seu impacto, e elaborar estratégias apropriadas para o seu engajamento } \\
\text { eficaz. }\end{array}$ \\
\hline
\end{tabular}

Fonte: Elaborado pelos autores a partir do $\operatorname{PMBOK}(2017$, p. 553).

Cada área de conhecimento é definida de acordo com seus requisitos de conhecimento, sendo compostas pelas seguintes ações: práticas, entradas, saídas, ferramentas e técnicas.

\subsection{GERENCIAMENTO DE PROJETOS E ELABORAÇÃO DO PDI: ESTUDOS CORRELATOS}

Os autores Mello et al. (2013) realizaram uma pesquisa na qual buscaram descrever o processo de planejamento (PDI) e o contexto de três universidades participantes da 
Associação de Universidades Grupo Montevideo - AUGM, localizadas em países da América Latina - Argentina, Brasil e Chile. Os resultados evidenciaram que as Instituições da Argentina e do Chile elaboram o PDI por interesse e no Brasil é por força de lei. Destacou-se também que existem disparidades na forma de implementação e execução do planejamento entre as universidades. Na UNL da Argentina, há o maior contingente de alunos das três universidades pesquisadas, quase o dobro da UFSM; a UFSM possui um quadro de servidores quase três vezes maior que a UNL.

Com intuito de investigar se a elaboração do planejamento estratégico de universidades federais brasileiras possui peculiaridades da Gestão de projetos, os autores Silva et al. (2014) entrevistaram in loco gestores de 8 universidades federais que participaram do processo de elaboração do planejamento estratégico de suas IES. Os resultados sugerem que os planejamentos são estratégicos e que seus escopos apresentam fortes características da administração de projetos (CONSUNI). As fases de inicialização e término da elaboração do planejamento são similares entre as instituições, inexistindo modelo padrão de confecção do planejamento estratégico, havendo uma customização à realidade de cada universidade. $\mathrm{O}$ início e término do processo de elaboração do planejamento estratégico seguem os princípios da administração de projetos, mas os meios deixam a desejar, o que causa rejeições após a finalização e prejudica a sua aceitação e implementação.

Bontempo, Moscardini e Sales (2015) realizaram uma análise comparativa do PDI do Instituto Federal de Educação de Minas Gerais (IFSULDEMINAS) com as metodologias de Planejamento Estratégico. O estudo avaliou o papel desempenhado pelo PDI nessa instituição e se esse instrumento pode ser visto como um planejamento estratégico. O estudo de caso incluiu entrevistas com gerentes atuais do IFSULDEMINAS e análise de documentos organizacionais. Os achados demonstram que as metodologias do PDI e Planejamento Estratégico são semelhantes em seu processo de desenvolvimento. No entanto, foi possível concluir que a metodologia PDI ainda exige melhorias.

Siedschlag, Silva Junior e Alves (2016) investigaram como a implementação de um Escritório de Gerenciamento de Projetos (EGP) pode colaborar na gestão estratégica de uma Universidade Comunitária de Santa Catarina. Os achados sinalizam que por meio do planejamento estratégico definem-se ações e projetos visando alcançar os objetivos organizacionais. Desta forma, a implantação de um EGP pode colaborar de maneira positiva 
no acompanhamento da execução, gerenciamento e aplicação das boas práticas de gestão estratégica, alinhados a missão e visão da organização.

\section{PROCEDIMENTOS METODOLÓGICOS}

A presente pesquisa configura-se, quanto aos procedimentos, como um estudo de casos múltiplos, uma vez que este método propicia ao pesquisador evidências com relação a diferentes contextos, no entanto, requer mais tempo para coleta de dados, pois faz-se necessário a replicação das mesmas questões para os todos os casos (GIL, 2008). O estudo de casos múltiplos, diversos estudos acontecem concomitantemente, com vários sujeitos e organizações (YIN, 2001).

Quanto ao problema, caracteriza-se como qualitativa, pois "há uma relação dinâmica entre o mundo objetivo e a subjetividade do sujeito que não pode ser traduzido em números" (PRODANOV; FREITA, 2013, p. 70). Lakatos e Marconi (2010) explicam que a metodologia qualitativa, normalmente, está relacionada com o estudo de caso, e utiliza-se dos instrumentos de observação, entrevista e história de vida para coleta de dados.

Em relação aos objetivos, caracteriza-se descritivo, visto que se realiza um estudo mais detalhado, e "tem como objetivo primordial a descrição das características de determinada população ou fenômeno ou, então, o estabelecimento de relações entre variáveis" (GIL, 2008, p. 28). Para essa análise e descrição dos resultados é necessário que os registros sejam realizados de forma cuidadosa e sem manipulações (CERVO; BERVIAN; SILVA, 2007).

O contato inicial para pesquisa foi realizado com quatro instituições de ensino superior localizadas na cidade de Chapecó-SC, as quais foram selecionadas pelo método intencional (CRESWELL, 2007). O critério de escolha das universidades sucedeu-se de modo a contemplar naturezas jurídicas distintas - particular, pública estadual, pública federal e comunitária (CANTON, 2019) - e, posteriormente, pelo fato da cidade de Chapecó abrigar em seu território os quatro tipos de personalidades jurídicas distintas. Em seguida foi realizado contato via telefone, mensagens via rede social ou e-mail para informar o objetivo da pesquisa e a importância de sua participação. Apenas três instituições concordaram em participar do estudo são as de personalidade jurídica pública federal, pública estadual e comunitária, indicadas como $\mathrm{A}, \mathrm{B}$ e $\mathrm{C}$, respectivamente. 
Como instrumento para coleta de dados, utilizou-se entrevista semiestruturada, por ser "uma técnica de interação social, uma forma de diálogo assimétrico, em que uma das partes busca obter dados, e a outra se apresenta como fonte de informação" (GERHARDT; SILVEIRA, 2009, p. 72), e, é guiada por um roteiro estabelecido de perguntas (GIL, 2008). Para validação do roteiro de questionário foi feita uma aplicação piloto a três gestores, o Diretor de Campus, o Ex-Diretor de Campus e a Coordenadora Administrativa de uma instituição pública, os quais participaram em anos anteriores da elaboração do PDI e da aprovação do documento, pois eram membros do CONSUNI.

$\mathrm{Na}$ presente pesquisa, as entrevistas foram realizadas com o Diretor de Planejamento (IES A), a Coordenadora de Apoio do Setor de Documentação e Normas (IES B) e Pró-reitor de Planejamento (IES C). Assim, de modo a preservar o sigilo da identidade das IES, optou-se por identificá-las como instituição: A, B e C. Os três participantes possuem expertise sobre o assunto em estudo, uma vez que atuaram diretamente na coordenação da elaboração do PDI em versões anteriores. Os dados foram coletados entre os meses de fevereiro e abril de 2020 , e as entrevistas duraram em média 50 minutos. Todas foram gravadas em áudio, com o consentimento dos participantes e ocorreram por meio de videoconferência via ferramenta Hangouts. Os gestores possuem entre 36 e 51 anos de idade e a fim de conservar suas identidades foram referenciados conforme o cargo que desempenham na instituição. O perfil de cada um dos entrevistados está apresentado no quadro 2.

Quadro 2 Perfil dos entrevistados

\begin{tabular}{|c|l|l|c|c|}
\hline Entr. & \multicolumn{1}{|c|}{ Cargo } & \multicolumn{1}{c|}{ Formação } & Tempo IES & IES \\
\hline 1 & $\begin{array}{l}\text { Diretor de } \\
\text { Planejamento }\end{array}$ & $\begin{array}{l}\text { Graduação em Administração e economia; pós- } \\
\text { graduação contabilidade pública e responsabilidade } \\
\text { fiscal, mestrado em políticas públicas e desenvolvimento } \\
\text { e doutorando em administração. }\end{array}$ & 10 anos & A \\
\hline 2 & $\begin{array}{l}\text { Coordenadora de } \\
\text { Apoio do Setor de } \\
\text { Doc. e Normas }\end{array}$ & Graduação e mestrado em Administração & 10 anos & B \\
\hline 3 & $\begin{array}{l}\text { Pró-Reitor de } \\
\text { Planejamento e } \\
\text { Desenvolvimento }\end{array}$ & $\begin{array}{l}\text { Eraduação em Ciências Econômicas e mestrado em } \\
\text { Economia }\end{array}$ & 19 anos & C \\
\hline
\end{tabular}

Fonte: Dados da pesquisa. 
Após a coleta de dados, as entrevistas foram transcritas de forma literal e, posteriormente, as informações foram compiladas e associadas ao objetivo proposto, bem como confrontadas à luz da fundamentação. Analisou-se os dados por meio da técnica de análise de conteúdo, que adota procedimentos sistemáticos e objetivos de descrição de conteúdo das mensagens (BARDIN, 2011), os quais buscam evitar a subjetividade do pesquisador que possa interferir nos resultados do estudo (RICHARDSON et al., 2014). Na etapa de análise seguiu-se a sequência contínua de cada processo do ciclo de vida do projeto, conforme o construto apresentado no quadro 3. Destacam-se os grupos de processos do gerenciamento de projetos, o conceito básico de cada processo na sequência contínua do ciclo de vida do projeto, bem como as questões da pesquisa que correspondem a cada processo e que nortearam a análise da contribuição do Gerenciamento de Projetos na elaboração do PDI.

Quadro 3 Construto da pesquisa

\begin{tabular}{|c|c|c|}
\hline $\begin{array}{l}\text { Grupos de Proc. } \\
\text { de Projetos }\end{array}$ & Conceito & Questões de Pesquisa \\
\hline \multirow{3}{*}{ Iniciação } & \multirow{3}{*}{$\begin{array}{l}\text { Caracteriza-se pelo início do } \\
\text { processo, a partir de um } \\
\text { conjunto de percepções e } \\
\text { interesses que compreendem o } \\
\text { estímulo à autorização do } \\
\text { projeto (VALERIANO, 2001). }\end{array}$} & $\begin{array}{l}\text { Quais são os primeiros procedimentos para se iniciar a } \\
\text { elaboração do PDI? }\end{array}$ \\
\hline & & $\begin{array}{l}\text { Quais membros compõem a comissão/equipe que irá } \\
\text { elaborar o PDI? }\end{array}$ \\
\hline & & $\begin{array}{l}\text { Quais são os critérios utilizados para escolha dos } \\
\text { membros da comissão? }\end{array}$ \\
\hline \multirow{4}{*}{ Planejamento } & \multirow{4}{*}{$\begin{array}{l}\text { Neste processo é elaborado de } \\
\text { forma criteriosa o escopo do } \\
\text { projeto, estabelecendo o que } \\
\text { fazer, como, quando, por quem, } \\
\text { por quanto, em quais condições } \\
\text { e outras definições } \\
\text { (VALERIANO, 2001; SILVA } \\
\text { et al, 2014). }\end{array}$} & $\begin{array}{l}\text { São definidas as funções e responsabilidades de cada } \\
\text { um dos envolvidos no projeto? }\end{array}$ \\
\hline & & $\begin{array}{l}\text { É montado um cronograma do projeto contendo o } \\
\text { sequenciamento e duração das atividades? }\end{array}$ \\
\hline & & $\begin{array}{l}\text { Como são planejadas as etapas para elaboração do } \\
\text { PDI? }\end{array}$ \\
\hline & & $\begin{array}{l}\text { Quanto tempo, geralmente, a comissão dispõe para } \\
\text { elaboração do PDI? }\end{array}$ \\
\hline \multirow[t]{2}{*}{ Execução } & \multirow{2}{*}{$\begin{array}{l}\text { Processo em que visa integrar a } \\
\text { equipe e os recursos a fim de } \\
\text { realizar o que foi previamente } \\
\text { planejado (VALERIANO, } \\
\text { 2001; PMI, 2017). }\end{array}$} & $\begin{array}{l}\text { Como foram desenvolvidas as etapas de execução do } \\
\text { PDI? }\end{array}$ \\
\hline & & Quem efetivamente participou de elaboração do PDI? \\
\hline \multirow{2}{*}{$\begin{array}{l}\text { Monitoramento e } \\
\text { controle }\end{array}$} & \multirow{2}{*}{$\begin{array}{l}\text { Processos em que a execução é } \\
\text { acompanhada e analisada, } \\
\text { visando controlar o } \\
\text { desempenho do projeto e, se } \\
\text { necessário, realiza-se os ajustes } \\
\text { ao plano (VALERIANO, 2001; } \\
\text { PMI, 2017). }\end{array}$} & $\begin{array}{l}\text { São realizadas reuniões para verificar o andamento dos } \\
\text { trabalhos e verificar seu status com o cronograma } \\
\text { proposto na fase de planejamento? Como? Quem } \\
\text { participa? }\end{array}$ \\
\hline & & $\begin{array}{l}\text { Após a elaboração da minuta a comissão se reúne para } \\
\text { revisão? }\end{array}$ \\
\hline \multirow{2}{*}{ Encerramento } & \multirow{2}{*}{$\begin{array}{l}\text { Processo em que o projeto é } \\
\text { formalmente concluído } \\
\text { (VALERIANO, 2001; PMI, } \\
\text { 2017). }\end{array}$} & $\begin{array}{l}\text { Como ocorre o processo de conclusão e aprovação do } \\
\text { PDI? }\end{array}$ \\
\hline & & $\begin{array}{l}\text { É realizada a avaliação das atividades de elaboração } \\
\text { do PDI? Como ocorre? }\end{array}$ \\
\hline
\end{tabular}

Fonte: Elaborado pelos autores. 


\section{ANÁLISE E INTERPRETAÇÃO DOS RESULTADOS}

Nesta seção, inicialmente, descreve-se os principais achados por IES conforme os cinco grupos de processos que contemplam o ciclo de vida do projeto e, apresenta-se uma discussão sobre os resultados com base na análise conjunta das três instituições.

\subsection{PRINCIPAIS ACHADOS POR IES}

\subsubsection{Instituição A}

Na primeira etapa, "Grupo de Processos de Iniciação”, buscou-se identificar quais são os primeiros trâmites e como acontece a formalização do início do processo de elaboração do PDI, bem como quais são as partes interessadas. O entrevistado 1 explica que "[...] o primeiro trabalho é analisar quais desses textos estão desatualizados, quais políticas não refletem mais a realidade, que tiveram alterações e quais precisam ser incorporadas ao documento". Comenta ainda, que "a incumbência de coordenar o processo de elaboração do PDI está com a Pró-reitora de Planejamento (PROPLAN), isso está previsto em Estatuto e Regimento Geral [...]" e que há "uma equipe interna mais especificamente lotada na Diretoria de Planejamento a qual é responsável por coordenar o processo de elaboração do PDI.”

No primeiro PDI de 2012 a 2016, prorrogado até 2018, elaborou-se uma série de audiências públicas em todos os Campi. No último PDI "foi um pouco diferente, como a segunda Conferência de Ensino, Pesquisa e Extensão (COEPE) já foi pensada para incorporar o seu texto ao PDI, então nós não fizemos uma nova rodada nos Campi nós aproveitamos o que foi produzido da conferência." Quanto à representatividade institucional, "[...] a participação no primeiro PDI foi livre nas audiências, qualquer pessoa podia participar e se manifestar via audiência, [...] no caso do segundo PDI se deu a partir da COEPE a qual também ocorreu por meio de audiências nos Campi, e os convites foram estendidos a todas as partes interessadas envolvendo a comunidade acadêmica, sendo livre, aberta a participação e sem critérios.".

Nota-se que a Instituição "A" possui uma equipe de competência técnica com alto grau de qualificação lotados na PROPLAN, baseado no exposto pelo participante “[...] hoje por exemplo nós somos ao todo seis pessoas, e destas, quatro pessoas são mestres e 2 doutorandos [...].'Informa ainda, que “geralmente quem coordena o trabalho de desenvolvimento é o Pró-reitor de Planejamento e o Diretor de Planejamento”. 
Com relação às atividades vinculadas ao processo de planejamento pode-se constatar que a instituição define as funções e responsabilidades de forma informal, visto que não é elaborado um projeto para desenvolver o PDI. "Nós temos uns documentos que são internos, mais uma espécie cronograma aonde a gente coloca quais as etapas vão ser desenvolvidas e quem vai fazer o que, como se fosse uma reunião de trabalho da equipe. [...]”. Assim, "as etapas são divididas conforme as próprias demandas de trabalho dos setores, não tem uma equipe exclusiva pra cuidar 40 horas por semana do PDI.".

Dessa forma, o cronograma estabelecido não possui prazos tão rígidos, podendo ser flexível caso necessário. O Diretor relatou que " [...] na prática o tempo dentro de uma sistemática para elaboração do PDI o prazo é de um ano, podendo ter prorrogações.

Para elaboração do PDI a Instituição “A” utiliza durante o processo de planejamento, o PDI do exercício anterior, bem como diversos outros documentos, como por exemplo as informações coletadas a partir da COEPE e algumas informações de caráter micro da avaliação institucional. Na última versão do PDI as etapas foram planejadas, "buscando fazer alterações mais de âmbito textual, e, em seguida foram coletadas informações mais técnicas (de dados, orçamento, estrutura física, questões pedagógicas)". E complementa que "após essa fase elaborou-se uma minuta de versão preliminar. A próxima etapa foi encaminhar essa versão do PDI a todos os Campi para que se produzissem debates a partir dessa minuta [...].”.

Quanto aos elementos tais como construção de visão, missão, análise de ambiente interno e externo "o conceito de planejamento estratégico adotado na universidade é um conceito de criação de futuro, a gente não baliza o que está no PDI conforme os orçamentários [...] a missão da universidade que perdurou durante as duas versões do PDI estão muito ligadas às origens a esta instituição [...].

Com relação às atividades do processo de execução buscou-se verificar como foram desenvolvidas as etapas desse processo, bem como realizou-se a publicidade institucional sobre a proposta do PDI. O Diretor de Planejamento explica que "é feito um cronograma das atividades por etapas, [...], com toda equipe diretiva seja da Reitoria ou dos Campi, a partir dali a gente colhe contribuições de etapas que podem vir a ser sugeridas [...]". Conforme o diretor, por meio do site institucional também são divulgadas as descrições de cada etapa para conhecimento da comunidade universitária.

Ao examinar o processo de monitoramento ou controle, o Diretor da PROPLAN contextualiza que essa fase ocorre "Através de duas outras peças de planejamento que são é o 
Plano Plurianual e o Planejamento anual. [...]. Contudo temos a partir deste ano uma nova ferramenta chamada fórum PDI, [...] no âmbito do Forplad (Fórum de Pró-Reitores de Planejamento e Administração) onde é possível [...] ir acompanhando como está sendo executado.". A fim de verificar o andamento dos trabalhos e monitorar seu status com o cronograma planejado durante a elaboração da minuta, o documento é revisado diversas vezes até a versão final.

Por fim, o processo de encerramento das atividades de elaboração do PDI consiste basicamente em tentar alinhar o que há de divergente, definir o texto final e encaminhar ao CONSUNI, que é órgão competente pela aprovação do PDI. O Diretor explica que "a conclusão se dá a partir das definições que o CONSUNI faz.” Quanto a avaliação das atividades durante e após a conclusão da elaboração do documento "a gente procura fazer não somente no final, mas a cada etapa [...]". Dessa forma, pode-se perceber o envolvimento integrado da equipe em todas as fases do processo, desenvolvendo um trabalho crítico e de revisão a todo momento.

\subsubsection{Instituição B}

O processo de iniciação da elaboração do PDI dá-se a partir da emissão de portaria para designação da comissão responsável. A coordenadora explica que "define-se o coordenador da comissão, que geralmente é designado o vice-reitor da instituição. A comissão é composta por representantes de todas as Pró-reitoras (ensino, pesquisa, pós-graduação, administração, extensão), além da coordenação da gestão acadêmica. Destaca-se que a representatividade institucional se dá por meio de consulta pública, a qual é disponibilizada no site da universidade à toda comunidade acadêmica durante a construção do documento para análise e sugestões. Além disso "[..] nós encaminhamos para os diretores gerais para eles de alguma forma verificarem nos centros, mas a grande contribuição da comunidade acadêmica foi por meio desta consulta pública."

Quanto às atividades do processo de planejamento, observa-se que há divisão de tarefas e responsabilidades entre os envolvidos conforme suas áreas de atuação no projeto de elaboração do PDI. Nota-se que a instituição "B" utiliza o PDI anterior como base para elaboração da versão atual, bem como considera a avaliação institucional para incorporar informações ao Plano Institucional. Durante a etapa de planejamento a universidade em estudo montou um cronograma do projeto contendo o sequenciamento e duração das 
atividades o qual precisou ser postergado em função de outras demandas paralelas. Desde o início dos trabalhos até a aprovação o prazo estimado foi de aproximadamente 1 ano e 4 meses.

Percebe-se ainda que a equipe não estipula um cronograma rígido para execuções das atividades, bem como seu acompanhamento dá-se de maneira informal, podendo ser flexibilizado conforme o andamento da coleta de informações. Geralmente acontecem reuniões a cada 45 dias para análise e orientação dos trabalhos e "O cronograma fica no controle de quem tá desenvolvendo, a gente sabe que vai passar por reuniões, uma reunião é em torno de 1 mês e meio. [...] a gente tinha cronograma e a gente foi de forma, não formalmente mudando esse cronograma."

Verifica-se que a universidade em análise busca planejar as etapas de elaboração do PDI considerando a visão e missão institucional, assim como analisa os ambientes interno e externo: "no momento a gente tá fazendo o novo planejamento estratégico da instituição e a gente vai fazer pequenas alterações na nossa missão e na nossa visão [...].

No tocante ao processo de execução as etapas de elaboração foram desenvolvidas e estruturadas conforme os eixos temáticos estabelecidos pelo MEC. Levou-se em consideração o Plano de Gestão em vigor. Quando indagada sobre a participação efetiva na elaboração tanto da comunidade externa quanto interna, a entrevistada argumenta “[...] a elaboração foi mais interna mesmo, não tivemos necessariamente [...] associações de fora que trabalharam no PDI foi só uma atividade interna." Outro ponto importante refere-se à representatividade institucional do PDI durante sua elaboração, a qual deu-se por meio de consulta pública à comunidade acadêmica a fim de divulgação e participação da comunidade na construção do documento.

Com relação ao processo de monitoramento ou controle, a coordenadora menciona que o controle "é só na planilha mesmo, não temos nenhum software, nenhum programa pra acompanhamento. É, a gente trabalha um relatório de gestão também e a gente verifica o que foi feito o que não foi feito, as ações que foram realmente implementadas." O andamento dos trabalhos é realizado pelos grupos de trabalhos ou subdivisões organizadas por Pró-reitoras em concomitante com outras atividades dos setores e “ a gente não reúne a equipe toda né, [...] a gente verifica as ações que estão sendo concretizadas e as ações relacionadas a ensino, por exemplo, o acompanhamento fica com o pessoal do ensino junto com o planejamento 
[..]”. Após a elaboração da minuta enviá-se o documento a todos os membros da comissão para considerações e revisão.

Por fim, apresenta-se as atividades relacionadas ao processo de encerramento da elaboração do PDI, às quais se dão pela aprovação do documento no CONSUNI.

Contudo, após a conclusão dos trabalhos percebe-se que a equipe não realiza a avaliação final das atividades: "era pra ter feito essa meta-avaliação, mas eu vou confessar que a gente não fez, [...], mas eu acredito que quando a gente for iniciar o próximo trabalho a gente vai ver o que a gente fez de bom e ruim no anterior pra gente poder ter uma atividade."

\subsubsection{Instituição C}

$\mathrm{Na}$ última instituição analisada, a elaboração do PDI inicia com a verificação da legislação vigente, estabelecimento de metodologia de trabalho, cronograma e indicação democrática e representativa dos membros que irão compor as subcomissões. A ocupação de cargos de gestão e experiências anteriores em setores administrativo e acadêmicos são alguns dos critérios estabelecidos para a escolha dos colaboradores. Isso pode ser confirmado na fala do pró-reitor de planejamento e desenvolvimento “ Primeira coisa é sempre ver o que que está sendo regulamentado em termos [...] de legislação nacional, $[\ldots]$ depois $[. .$.$] metodologia de$ trabalho, $[\ldots]$ com cronograma de tempo, e aí [...] as pessoas são nomeadas por portaria”; “ [...] a gente tenta contemplar todos os segmentos de pessoas [...] que tenha passado por um cargo de gestão, alguma experiência, de algum trabalho realizado na instituição [...]”; “[...] $\mathrm{O}$ suficiente é que a gente consiga na sua elaboração ter um instrumento participativo[...]”.

$\mathrm{Na}$ fase de planejamento dos trabalhos, segue-se o que rege a resolução do PDI, os temas são subdivididos entre as comissões e tudo é coordenado pelo presidente da comissão. Ele afirma que "[...] uma condição necessária para coordenar uma comissão é ter uma visão bastante sistêmica da instituição"; “[...] a gente pega a resolução que rege o PDI, [...] fatia isso em temas, elege um presidente para cada tema e cria subcomissões de trabalho [...]." O PDI anterior e a avaliação institucional são consultados para observar erros e acertos ocorridos no passado. Depois, faz-se um planejamento que contempla várias etapas a serem cumpridas. Também se verifica o planejamento estratégico. O documento é elaborado anteriormente e confrontado no momento de fazer o PDI. 
Nesse sentido, o cronograma é trabalhado no formato de um projeto. É feito um check list para dar norte ao curso das atividades, possíveis mudanças e acompanhamento das tarefas a serem executadas pelas subcomissões. A diretoria de planejamento é que acompanhava e prestava apoio às comissões. O pró-reitor afirma: “[...] O PDI assim como outros projetos é trabalhado como um projeto, [...] e a gente prepara um cronograma antes de tudo, da execução dele, o prazo que a gente vai entregar esse projeto"; “[...] na comissão, ela tem autonomia pra mudar cronograma, mudar metodologia, [...] corrigir algum viés que tenha em termos de redação [...]"; "no último PDI a gente fazia reunião praticamente semanal [...] a gente chamava os coordenadores das subcomissões pra conversar, a gente estartava um, [...] manualzinho do que precisava ser feito [...]”.

No que tange ao tempo destinado à elaboração do documento, o pró-reitor observa o interesse da instituição e a necessidade de um prazo mínimo para realização de um trabalho satisfatório. Além disso reforça que as atividades são realizadas concomitantemente ao trabalho dos membros da comissão. “[...] o cronograma ele vai muito da necessidade de ter prazo pra dialogar com os segmentos, porque ele tem que ser participativo e de acordo com o prazo institucional. [...] é difícil fazer em menos de 6 meses".

No momento de execução das etapas planejadas o entrevistado reforça 0 acompanhamento dos trabalhos por parte da comissão que coordena todas as atividades, como pode ser observado na sua fala"[...] A gente faz um planejamento, repassa as atividades pro coordenador, o coordenador chama o grupo e vão executando o passo a passo, a gente ia monitorando semanalmente e quinzenalmente."

Também é atribuída grande importância a forma como é feita a fase de divulgação, em função da necessidade de o documento requisitar a participação de toda a comunidade acadêmica e uma parte da comunidade externa. "[...] Todo mundo na instituição tem que saber que o PDI está sendo feito, elaborado. E inclusive os momentos [...] apresentações e seminários com a participação do público, isso tem que ser muito bem divulgado, com várias datas, [...] que a pessoa possa ir lá contribuir também [...].” Em sua fala o pró-reitor ainda esclarece alguns meios utilizados para dar ampla publicidade à atividade. "E-mail, criamos uma página específica pro PDI, onde as pessoas podiam acompanhar, [...] contribuir com alterações no documento na primeira versão [...]". Observa-se que a representatividade da comunidade externa se deu por meio de representantes das instituições, e em relação à comunidade universitária procurou-se ouvir todas as instâncias. "[...] a gente fez um grupo 
focal com a comunidade externa, [...] os representantes das instituições, [...] foi bem interessante assim, a visão deles, e a gente fez seminários com todos os segmentos".

Para garantir o sucesso desse trabalho é enfatizado o aspecto de controle das atividades desenvolvidas a fim de garantir o cumprimento de prazos e andamento dos trabalhos da comissão. Quando ocorre o término da minuta do PDI o documento que é revisado constantemente durante sua elaboração, passa por uma conferência final. "Tinha a planilha, a gente mandava o roteiro e acompanhava a execução do coordenador com a sua comissão o tempo todo pra tentar cumprir a meta, [...]”; “A comissão de sistematização, [...] tinha essa preocupação de alinhar as coisas, de fazer um tema conversar com o outro [...]”. Ainda complementa “[...] esse foi o maior trabalho nosso, é é alinhar tudo isso, muitas reuniões até finalizar $[\ldots]$ ”.

$\mathrm{Na}$ última etapa, encerramento, o documento é entregue para a reitoria e encaminhado para aprovação dos órgãos consultivos e deliberativos da instituição. Caso haja necessidade de pequenas alterações estas são resolvidas de imediato “[...] estava previsto na portaria ali que a comissão de sistematização entregaria pra reitoria, e a reitoria encaminharia esse documento para os comitês [...]”; “[...] as alterações elas podem ser feitas na hora, [...] se tiver muita mudança, [...] a ponto de comprometer o documento, muitas vezes o que o presidente do conselho faz, retorna a origem [...]”.

Depois de encerrado os trabalhos, as equipes participam de um feedback, com o intuito de debater os aspectos positivos e negativos ocorridos no processo. O pró-reitor explica “[...]a gente faz especialmente com a equipe do trabalho ali, [...] essas reuniões a gente fazia durante e depois quando finalizou sim, pra ter um feedback geral do que aconteceu de bom, do que precisava melhorar".

\subsection{Aplicação do gerenciamento de projetos na elaboração do PDI}

O Gerenciamento de Projetos abrange cinco grupos utilizados para nortear a equipe na operacionalização das atividades e supervisionar os transmites até atingir os objetivos do projeto. Nesse sentido, analisa-se de forma conjunta os três casos pesquisados de acordo com cada grupo.

Ao analisar o Grupo de Processos de Iniciação, observa-se que os resultados indicam que as três IES estudadas utilizam os procedimentos iniciais muito semelhantes, corroborando com os achados de Silva et al. (2014). As atividades iniciam-se pela análise de 
conteúdo em observância às normativas vigentes, bem como a coordenação das atividades fica a cargo da Pró-reitora de Planejamento em conjunto com outros membros que possuem competência técnica qualificada, experiências anteriores com o PDI e que atuam em áreas afins ao projeto. A equipe, geralmente, é coordenada pelo Pró-Reitor ou diretor de Planejamento. O início do trabalho nas Universidade "B" $\mathrm{e}$ "C $\mathrm{C}$ " ocorre por meio de portaria de designação, e na universidade "A" a incumbência está prevista em regulamento.

Todas as instituições, durante a elaboração do PDI, buscaram contemplar a representatividade institucional, de forma a abranger todos os segmentos da comunidade universitária, ou seja, buscaram promover a participação de todas as partes interessadas no projeto. Como observou-se pela fala do Diretor de Planejamento da IES “A” "[...] o segundo PDI se deu a partir da COEPE a qual também ocorreu por meio de audiências nos Campi, as quais foram elaboradas pelas Direções e os convites foram estendidos as todas as partes interessadas envolvendo a comunidade acadêmica, sendo livre, aberta a participação e sem critérios."

Visto que a elaboração de um plano sumário é fundamental no processo de iniciação, de acordo com o (PMI, 2017), os achados contemplam a literatura no que se refere ao gerenciamento da integração, do escopo, de recursos, das comunicações, dos riscos e das partes interessadas (PMI, 2017). Além disso, é possível verificar a formalização do projeto e a autonomia dada à equipe na condução dos trabalhos (LIMA, 2010).

Quanto ao processo de planejamento nota-se que as três IES definem funções e responsabilidades para os membros da equipe. No entanto, as instituições adotam metodologias distintas, uma vez que na instituição "A" divide-se as tarefas entre os membros lotados na PROPLAN, na instituição "B" dois colaboradores lideraram os trabalhos com o auxílio dos Pró-Reitores, e na Instituição "C" compõe-se subcomissões por temas de trabalho designando um coordenador por pasta. Observa-se que o cronograma estabelecido pelas equipes é flexível, haja vista que os membros não atuam exclusivamente na elaboração do documento. "As etapas são divididas conforme as próprias demandas de trabalho dos setores, não tem uma equipe exclusiva pra cuidar 40 horas por semana do PDI." (ENTREVISTADO 1)

As etapas do Planejamento procuraram atender as normativas governamentais, seguidas da visão, missão e diretrizes institucionais. Depreende-se que neste momento, todas as instituições buscaram definir atividades que envolveram a construção do documento ou 
projeto, seus requisitos e objetivos, os processos técnicos e administrativos, e a definição da equipe de trabalho (VALERIANO, 2001). Observa-se que esta etapa apresenta as características previstas no PMI (2017) tais como: definição do escopo do projeto, delineamento dos objetivos e ações, coleta informações e integração das partes interessadas. No entanto, nota-se que o escopo e o cronograma não são elaborados de maneira formal e suas etapas também não apresentam detalhamento, conforme descrito no guia. Ainda, não é realizado o gerenciamento de custos, considerando a natureza do projeto.

No tocante ao processo de execução, os achados revelam que o desenvolvimento das etapas visa coletar e repassar informações para incorporar ao PDI. Constata-se ainda, que no caso da instituição "A" a coordenação das atividades fica exclusivamente a cargo da PROPLAN, mas busca-se a representatividade por meio de consultas a demais Pró-reitoras, secretarias, os campi e organizadores da COEPE. Na instituição "B" os trabalhos são coordenados pela PROPLAN e demais Pró-reitoras e a instituição "C" as tarefas contemplam todos os segmentos institucionais, incluindo a comunidade externa. Confrontando esses resultados à luz da literatura, os elementos que convergem com os aspectos descritos no manual PMI (2017) são o gerenciamento das partes interessadas e a integração e execução das atividades do projeto em conformidade com o plano de gerenciamento do projeto. Nota-se que não há gerenciamento de recursos.

No que concerne ao processo de monitoramento e controle, constata-se que para conduzir a elaboração do PDI, a equipe utilizou-se de reuniões como uma das técnicas e ferramentas para alinhar-se ao escopo do trabalho, assim como verificar o status do cronograma (PMI, 2017). Todavia, após a elaboração da minuta verifica-se que as universidades A e B não reuniram toda a equipe para análise do PDI, sendo esse procedimento realizado de forma individual após o recebimento do documento por parte dos membros via ferramenta eletrônica, conforme explana o entrevistado 2 " a gente não reúne a equipe toda né, [...] a gente verifica as ações que estão sendo concretizadas e as ações relacionadas a ensino, por exemplo, o acompanhamento fica com o pessoal do ensino junto com o planejamento [...”. Por outro lado, a universidade C revelou realizar várias reuniões presenciais para alinhar e dar coerência ao texto redigido.

Ao analisar o processo de encerramento, verifica-se que todas a instituições de ensino dessa pesquisa concluem formalmente a elaboração do PDI por meio da aprovação do documento por parte da instância superior do colegiado, respeitando as disposições da 
legislação federal (SILVA et al., 2014). Assim, define-se formalmente a conclusão do projeto conforme estabelecido pelo PMI (2017).

A partir dos resultados oriundos da análise qualitativa nota-se que as informações encontradas no processo de iniciação aproximam-se dos achados da pesquisa de SILVA et al., (2014) no que se refere a constituição da equipe. No entanto, há divergências quanto ao envolvimento das partes interessadas e a comunicação, uma vez que se observou problemas de comunicação devido à baixa participação dos segmentos institucionais acarretaram a reprovação do documento elaborado por parte do conselho superior.

Os resultados da presente pesquisa possibilitaram constatar que as universidades desenvolveram habilidades na comunicação, as quais fizeram uso de diferentes canais para publicizar o documento e promover a participação dos segmentos institucionais, inclusive à comunidade externa.

\section{CONSIDERAÇÕES FINAIS}

Este artigo analisou a contribuição da gestão de projetos na elaboração do plano de desenvolvimento institucional (PDI) em 3 Instituições de Ensino Superior, cujas personalidades jurídicas, eram: pública federal, estadual e comunitária.

A ferramenta utilizada para realização da pesquisa permitiu aos entrevistadores inferências com intuito de elucidar detalhes sobre as etapas de elaboração do PDI frente a gestão de projetos. Desta maneira, percebeu-se que o representante da instituição "A" possui conhecimento teórico em relação às ferramentas da gestão de projetos e conhecimento sobre o PDI. A entrevistada da IES "B" demonstrou experiência na elaboração do PDI, mas pouco conhecimento sobre o PMBOK. Por sua vez, na universidade "C", o pró-reitor demonstrou bastante conhecimento na formulação do documento, devido aos anos de experiência profissional na instituição e, também, ao conhecimento das ferramentas de gestão de projetos, ressaltando inclusive, que o ideal seria utilizar todas as ferramentas do guia PMBOK.

Os resultados mostraram que nas 3 instituições, o processo de elaboração do PDI passa pelas fases de início, meio e fim, evidenciando características de gerenciamento de projetos (VARGAS, 2009). Nesse mesmo sentido, foi possível constatar a presença do Gerenciamento de Projetos, por meio da execução dos cinco grupos (iniciação, planejamento, execução, monitoramento e conclusão) que permitem a operacionalização das atividades e transmites até atingir os objetivos propostos (PMI, 2017). 
$\mathrm{Na}$ análise desses grupos de processos percebeu-se a adoção de algumas áreas do PMBOK, ou seja, gerenciamento da integração, escopo, cronograma, recursos, comunicação, riscos e partes interessadas. Nesse sentido constatou-se que para o desenvolvimento das atividades de maneira eficaz é fundamental a utilização das seguintes ferramentas e técnicas: opinião especializada (expertise de indivíduos ou grupos com conhecimento ou treinamento especializado), coleta de dados (brainstorming, listas de verificação, grupos de discussão e entrevistas), habilidades interpessoais e de equipes (gerenciamento de conflitos e facilitação) reuniões, gerenciamento de informações e de conhecimentos (conectam pessoas para trabalhar juntas e criar novos conhecimentos).

As instituições não possuem escritório de gestão de projetos. Os membros das comissões que atuam na elaboração do PDI não trabalham exclusivamente nesta tarefa, a realizam concomitantemente com outras demandas institucionais.

No cômputo geral, verifica-se que os achados indicam que o gerenciamento de projetos pode colaborar no processo dessa elaboração (SILVA et al., 2014), uma vez que a elaboração do PDI segue sistematicamente as fases de início, meio e fim (VERZUH, 2000; HELDMAN, 2005; VIANA, 2005; FIGUEIREDO, FIGUEIREDO, 2003; VARGAS, 2009; SILVA et al., 2014; PMI, 2017), visto que um projeto pode ser compreendido como um conjunto de atividades correlacionadas visando alcançar um objetivo temporal pré determinado.

Diante do exposto, pode-se concordar com os argumentos de Pisa (2013) que a Gestão de Projetos potencializa o desempenho da elaboração e execução de projetos, no entanto, é essencial que haja uma mudança gradual da cultura institucional visando a adoção da gestão de projetos, formação de equipes e líderes de alto desempenho.

Como sugestão para pesquisas futuras recomenda-se ampliar a amostra, fazer um comparativo entre instituições que possuem e aquelas que não possuem escritório de gerenciamento de projetos.

\section{REFERÊNCIAS}

BARDIN, L. Análise de conteúdo. São Paulo: Edições 70, 2011.

BONTEMPO, P. C; MOSCARDINI, S. B.; SALLES, J. A. A. Comparative analysis between the institutional development plan and strategic planning methodologies: the case of the Federal Institute of Education at Minas Gerais - Brazil. Procedia - Social and Behavioral Sciences, v. 174, p. 2962 - 2966, 2015. Doi: 10.1016/j.sbspro.2015.01.1035 
BRASIL, Lei no . 10.861, de 14 de abril de 2004. Dispõe sobre o exercício das funções de regulação, supervisão e avaliação das instituições de educação superior e dos cursos superiores de graduação e de pós-graduação no sistema federal de ensino.Disponível em: $<$ http://www.planalto.gov.br/ccivil_03/_Ato2015-2018/2017/Decreto/D9235.htm>. Acesso em 01 jun. 2020.

CANTON, V. I. de M. A contribuição da universidade no ensino do empreendedorismo pelo perfil empreendedor dos acadêmicos. Chapecó: UNOCHAPECÓ, 2019. $161 \mathrm{f}$. Dissertação (Mestrado em Ciências Contábeis e Administração) - Universidade Comunitária da Região de Chapecó, Chapecó, 2019.

CARVALHO, K. E. M.; PISCOPO, M. R. Fatores de Sucesso da Implantação de um PMO: um caso na Administração Pública: Gestão \& Tecnologia, v. 14, p. 56-78, 2014.

CERVO, A. L.; BERVIAN, P. A.; SILVA, R. da. Metodologia

científica. 6. ed. São Paulo: Pearson Prentice Hall, 2007.

CRESWELL, J. W. Projeto de pesquisa: métodos qualitativo, quantitativo e misto. 2. ed.

Porto Alegre: Artmed, 2007.

GERHARDT, T. E.; SILVEIRA, D. T. Métodos de pesquisa. Porto Alegre: Editora da UFRGS, 2009.

GIL, A. C. Métodos e técnicas de pesquisa social. 6. ed. São Paulo: Atlas, 2008.

FIGUEIREDO, F. C. de; FIGUEIREDO, H. C. M. Dominando Gerenciamento de projetos com MS project 2002. São Paulo: Ciência Moderna LTDA., 2003.

HELDMAN, K. Gerência de projetos: guia para o exame oficial do PMI. Rio de Janeiro: Elservier, 2005.

LAKATOS, E. M.; MARCONI, M. de A. Fundamentos de Metodologia Científica. 7. ed. São Paulo: Atlas, 2010.

LIMA, R. J. B. Gestão de projetos. 1. ed. São Paulo: Pearson Education do Brasil, 2010. MAGRO, C. B. D.; RAUSCH, R. B. Plano de Desenvolvimento Institucional de Universidades Federais Brasileiras. Administração: Ensino e Pesquisa. Rio de Janeiro, v. 13, no 3, p. 427-454, jul/ago/set 2012.

MARTENS, M. L.; CARVALHO, M. M. Key factors of sustainability in project management context: A survey exploring the project managers' perspective. International Journal of Project Management, v.35, n. 6, p. 1084-1102, 2017.

MELLO, J. de; MADRUGA, L. R. da R. G.; ÁVILA, L. V., BEURON, T. A. Análise do Plano de Desenvolvimento Institucional de Instituições de Ensino Superior participantes da Associação de Universidades Grupo Montevideo - AUGM. Revista GUAL. Florianópolis, v. 6, n. 4, p. 01-22, Edição Especial. 2013. DOI: http://dx.doi.org/10.5007/19834535.2013v6n4p1 
OLIVEIRA, R. R.; CRUZ, J. E.; OLIVEIRA, R. R. Fatores Críticos de Sucesso na Gestão de Projetos: Análise dos Indicadores que Constituem os Predecessores da Estratégia, Pessoas e Operações. Revista de Gestão e Projetos, v. 9, n. 3, p. 49-66, 2018. DOI:

https://doi.org/10.5585/GeP.v9i3.11263

OLIVEIRA, R. R.; MARTINS, H. C.; OLIVEIRA, R. R.; DIAS, A. T.; GONÇALVES, C. A. Desempenho do escritório de gerenciamento de projetos: Um estudo comparativo entre as organizações nacionais e internacionais. ENCONTRO NACIONAL DA ASSOCIAÇÃO NACIONAL DE PÓS-GRADUAÇÃO E PESQUISA EM ADMINISTRAÇÃO, p. 1-17. Rio de Janeiro: ANPAD, 2018.

PISA, B. J.; OLIVEIRA, A. G. Gestão de Projetos na Administração Pública. In: $1^{\circ}$ Seminário Nacional de Planejamento e Desenvolvimento ( $1^{\circ}$ SNPD), 2013, Curitiba. Anais do SNPD. Curitiba: PPGP/UTFPR, 2013. v. 1.

PMI-PROJECT MANAGEMENT INSTITUTE. Um Guia do Conhecimento em Gerenciamento de Projetos (Guia PMBOK). 6. ed. Pensilvânia: PMI, 2017.

PRODANOV, C. C.; FREITAS, E. C. de; Metodologia do Trabalho Científico: e Técnicas da Pesquisa e do Trabalho Acadêmico. 2. ed. Novo Hamburgo: Feevale, 2013.

SIEDSCHLAG, D; SILVA J.; OVIDIO F. P. Da; ALVES, C. S. R. A Contribuição do Escritório de Gestão de Projetos - EGP na Gestão Estratégica de uma Universidade Comunitária. Revista de Gestão e Projetos, v. 7, n. 3, 2016. DOI: https://doi.org/10.5585/gep.v7i3.335

SILVA, J. E. O.; et al. Conciliando Administração de Projetos com Planejamento Estratégico na Gestão de Universidades Federais Brasileiras. Revista GUAL, v. 7, n. 3, p. 93-114, 2014.

SILVA, J. E. O. Contribuições do plano de desenvolvimento institucional e do planejamento estratégico na gestão de universidades federais brasileiras. $150 \mathrm{p}$.

Dissertação (Mestrado em Administração) - Programa de Pós-Graduação em Administração, Universidade Federal de Santa Catarina, Florianópolis, 2013.

SILVA, V. do N.; RISSI, M. Gestão de projetos na gestão estratégica universitária: um estudo bibliométrico. Capital Científico - Eletrônica (RCCe), v. 17, n. 4, p. 44-64, 2019. Disponível em: <revistas.unicentro.br/index.php/capitalcientifico/index.> Acesso em 17 nov. 2019.

STOIAN, C.; GILMAN, M. Corporate social responsibility that "pays": A strategic approach to CSR for SMEs. Journal of Small Business Management, v. 55, n. 1, p. 5-31, 2017.

UNIVERSIDADE FEDERAL DE PERNAMBUCO - UFPE. Plano de Desenvolvimento Pedagógico da UFPE (PDI) 2019-2023. 2019. Disponível em: <https:/www.ufpe.br/planode-desenvolvimento-institucional-pdi> 26.02.2020. Acesso em $26 \mathrm{fev}, 2020$.

RICHARDSON, R. J.; et al. Pesquisa social: métodos e técnicas. 3. ed. São Paulo: Atlas, 2014. 
VALERIANO, D. L. Gerenciamento estratégico e administração por projetos. 1. ed. São Paulo: Makron Books, 2001.

VARGAS, R. V. Gerenciamento de Projetos: Estabelecendo diferenciais competitivos. Rio de Janeiro: Brasport, 7. ed. 2009.

VERZUH, E. MBA Compacto Gestão de Projeto. Rio de Janeiro: Campus, 2000.

VIANA, R. Gerenciamento de projetos: estabelecendo diferenciais competitivos. estabelecendo diferenciais competitivos. Rio de Janeiro: Brasport, 2005.

Turner, J. R. The Handbook of Project-Based Management. 3. ed. New York: McGrawHill Education, 2008.

TURNER, J.R.; MULLER, R. On the nature of the project as a temporary organization. International Journal of Project Management, v. 21, p. 1-8, 2003. DOI: 10.1016/S02637863(02)00020-0.

YIN, R. K. Estudo de caso: planejamento e métodos. 2. ed. Porto Alegre: Bookman, 2001. 